\title{
Assignment of Model Amygdala Neurons to the Fear Memory Trace Depends on Competitive Synaptic Interactions
}

\author{
Dongbeom Kim, ${ }^{1}$ Denis Paré, ${ }^{2}$ and Satish S. Nair ${ }^{1}$ \\ ${ }^{1}$ Department of Electrical and Computer Engineering, University of Missouri, Columbia, Missouri 65211, and ${ }^{2}$ Center for Molecular and Behavioral \\ Neuroscience, Rutgers, The State University of New Jersey, Newark, New Jersey 07102
}

We used biophysical modeling to examine a fundamental, yet unresolved, question regarding how particular lateral amygdala (LA) neurons are assigned to fear memory traces. This revealed that neurons with high intrinsic excitability are more likely to be integrated into the memory trace, but that competitive synaptic interactions also play a critical role. Indeed, when the ratio of intrinsically excitable cells was increased or decreased, the number of plastic cells remained relatively constant. Analysis of the connectivity of plastic and nonplastic cells revealed that subsets of principal LA neurons effectively band together by virtue of their excitatory interconnections to suppress plasticity in other principal cells via the recruitment of inhibitory interneurons.

\section{Introduction}

Classical fear conditioning is an experimental paradigm used to investigate how animals learn to fear new stimuli by experience. In this model, a neutral sensory stimulus [conditioned stimulus (CS) ] acquires the ability to elicit fear responses after a few pairings with a noxious stimulus [unconditioned stimulus (US)]. While there is evidence that fear conditioning induces widespread synaptic plasticity in the brain, including at thalamic and cortical levels (Letzkus et al., 2011; Weinberger, 2011), there are also data indicating that the dorsal portion of the lateral amygdala (LAd) is a critical site of plasticity for the storage of pavlovian fear memories (LeDoux, 2000; Pape and Paré, 2010). What is less clear is how particular LAd neurons are assigned to the fear memory trace. Indeed, relatively few LAd neurons (25\%) acquire an increased responsiveness to stimuli predicting adverse outcomes (Quirk et al., 1995; Repa et al., 2001; Rumpel et al., 2005), even though most receive the necessary inputs (Han et al., 2007).

In a previous study, we developed a biophysical LAd model that reproduced experimental findings regarding the cellular correlates of fear conditioning in LA (Fig. 1A-D; Kim et al., 2013). We used it to examine whether fear memories depend on (1) training-induced increases in the responsiveness of thalamic and cortical neurons projecting to LA, (2) plasticity at the synapses they form in LA, and/or (3) plasticity at synapses between LA neurons. These tests revealed that training-induced increases in

\footnotetext{
Received June 7, 2013; revised July 6, 2013; accepted Aug. 1, 2013.

Author contributions: D.P. and S.S.N. designed research; D.K., D.P., and S.S.N. performed research;D.K., D.P., and S.S.N. analyzed data; D.K., D.P., and S.S.N. wrote the paper.

This research was supported in part by National Institute of Mental Health Grants MH083710 to D.P. and MH087755 to S.S.N.

The authors declare no competing financial interests.

Correspondence should be addressed to Dr. Satish S. Nair, Electrical and Computer Engineering, University of Missouri, Columbia, M0 65211. E-mail: nairs@missouri.edu.

DOI:10.1523/JNEUROSCI.2430-13.2013

Copyright $\odot 2013$ the authors $\quad 0270-6474 / 13 / 3314354-05 \$ 15.00 / 0$
}

the responsiveness of afferent neurons are required for fear memory formation. However, once the memory has been formed, this factor is no longer required because the efficacy of the synapses that thalamic and cortical neurons form with LA cells has augmented enough to maintain the memory. In contrast, plasticity at synapses between LA neurons was found to play a minor role in maintaining the fear memory.

In the present study, we use the model to examine how particular LA neurons are assigned to fear memory traces. Previously, it was reported that LA cells expressing high levels of activated cAMP response element-binding protein (CREB; hereafter "activated CREB" is denoted as "CREB") are preferentially recruited into the memory trace (Han et al., 2007, 2009). In fact, the proportion of LA cells expressing CREB is similar to that acquiring potentiated responses to the CS in unit recording studies (Quirk et al., 1995; Repa et al., 2001; Rumpel et al., 2005). However, when CREB was overexpressed $\left(\mathrm{CREB}^{+}\right)$or downregulated $\left(\mathrm{CREB}^{-}\right)$in $\mathrm{LA}$, the proportion of LA neurons recruited into the memory trace did not change, suggesting that the assignment of particular LA neurons to the memory trace involves a competitive process (Han et al., 2007). Consistent with this, CREB enhances the intrinsic excitability of principal cells by inhibiting the slow afterhyperpolarization (sAHP) current (Viosca et al., 2009; Benito and Barco, 2010), without altering their membrane potential, input resistance, or spike shape (Zhou et al., 2009). Moreover, the latter study suggested that CREB increases the likelihood that principal cells will become part of the fear memory by enhancing their intrinsic excitability. In the present study, we used a realistic biophysical model of LAd to shed light on this question.

\section{Materials and Methods}

We provide a brief overview of the 1000-cell biophysical LAd model used in this study. The reader is referred to our prior study for a complete description (Kim et al., 2013). 

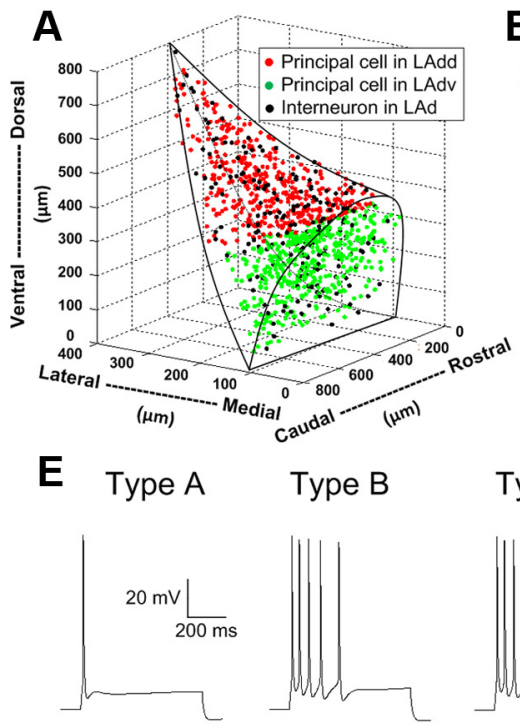

$300 \mathrm{pAL}$
B

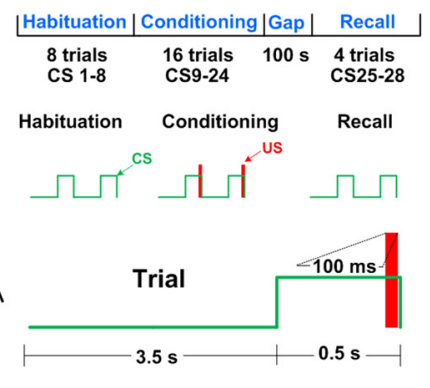

C

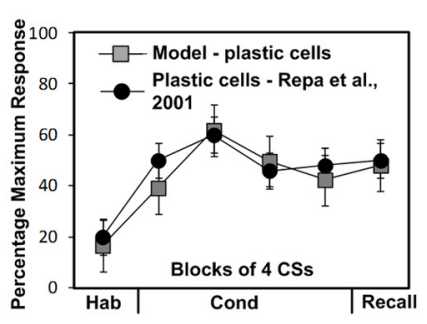

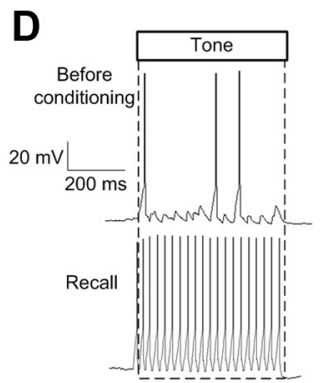

Type C $\quad \mathbf{F}$ Type A

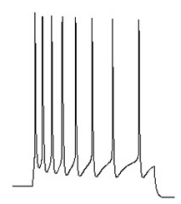

4

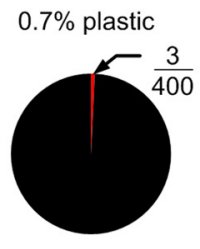

Plastic

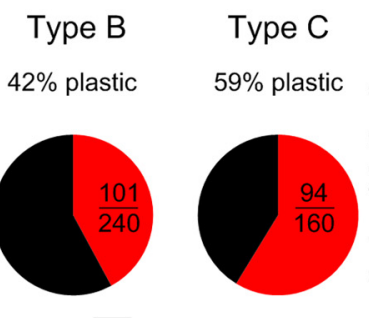

Non-Plastic

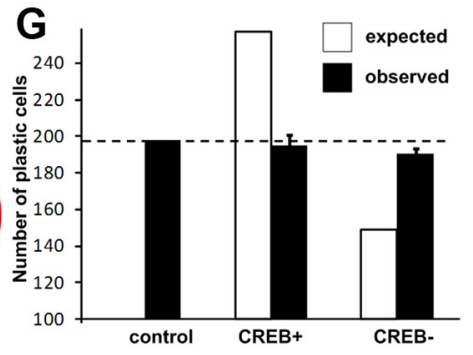

Figure 1. Spatial structure, intrinsic connectivity, and fear-conditioning protocol for the LAd network model. $A$, The model consists of 800 principal cells and 200 interneurons populated randomly in the horn-shaped LAd. B, Fear-conditioning protocol. $\boldsymbol{C}$, Average tone responses of plastic LAd cells during the different phases of the behavioral protocol. $\boldsymbol{D}$, Example of tone responses generated by a plastic cell during habituation (top) and recall test (bottom). $\boldsymbol{E}$, Repetitive firing dynamics of three types of model projection cells. $\boldsymbol{F}$, Proportion of plastic cells among the three types of projection cells. G, Expected (white) and observed (black) numbers of model plastic cells for the control, CREB ${ }^{+}$, and CREB ${ }^{-}$cases. Competition biases the observed numbers toward the control value.

\section{Single-cell models}

To reproduce to diversity of spike frequency adaptation seen in principal LA neurons (Faber et al., 2001; Faber and Sah, 2003; Power et al., 2011), we modeled three types of regular spiking principal cells, with high (type A), intermediate (type B), or low (type C) spike frequency adaptation, due to the differential expression of a $\mathrm{Ca}^{2+}$-dependent $\mathrm{K}^{+}$current. Within each class (A-C), all cells were endowed with the same conductance for this current, with the lowest value being for the more excitable type C cells (Kim et al., 2013). LA also contains local GABAergic interneurons that exhibit various firing patterns, even among neurochemically homogeneous subgroups (Pape and Paré, 2010). However, the majority display a fast-spiking pattern, which was reproduced in the model.

The principal cell model had three compartments representing a soma (diameter, $24.75 \mu \mathrm{m}$; length, $25 \mu \mathrm{m}$ ), an apical dendrite (diameter, 2.5 $\mu \mathrm{m}$; length, $119 \mu \mathrm{m}$ ) on which synapses were placed, and another dendrite (diameter, $5 \mu \mathrm{m}$; length, $400 \mu \mathrm{m}$ ) that helped match passive properties. Values of specific membrane resistance, membrane capacity, and cytoplasmic (axial) resistivity were within the ranges reported in previous physiological studies. The current types, equations, and densities, as well as the match of the single-cell model and experimental data for responses to various current injections can be found in recent reports ( $\mathrm{Li}$ et al., 2009; Kim et al., 2013).

The interneuron model had two compartments: a soma (diameter, 15 $\mu \mathrm{m}$; length, $15 \mu \mathrm{m}$ ); and a dendrite (diameter, $10 \mu \mathrm{m}$; length, $150 \mu \mathrm{m}$ ). The passive membrane properties were as follows: $\mathrm{R}_{\mathrm{m}}$ (membranespecific resistance) $=20 \mathrm{~K} \Omega-\mathrm{cm}^{2}, \mathrm{C}_{\mathrm{m}}$ (membrane-specific capacitance) $=1.0 \mu \mathrm{F} / \mathrm{cm}^{2}, \mathrm{R}_{\mathrm{a}}$ (membrane axial-specific resistivity) $=150$ $\Omega$-cm, and $\mathrm{E}_{\mathrm{L}}$ (leak current reversal potential) $=-70 \mathrm{mV}$. Similar to the pyramidal cell, the interneuron model could reproduce the nonadapting repetitive firing behavior of fast-spiking cells, as observed experimentally. Details, including currents used, have been reported separately (Kim et al., 2013).

\section{Network structure and connectivity}

It was estimated that there are 24,000 principal cells in LAd (Tuunanen and Pitkänen, 2000). To keep computation times practical while capturing the complexity of the intra-LAd network, we modeled a scaled down (30:1) version of LAd that included 800 principal cells. Because the proportion of interneurons to principal cells is $20: 80$, the model included
200 interneurons. Principal cells and interneurons were distributed randomly in a realistic tridimensional representation of the horn-shaped LAd (Fig. 1A). By comparing the responses of LA cells to local applications of glutamate at various positions with respect to recorded neurons, general principles were inferred for connectivity among principal cells, as well as between local-circuit and principal neurons (Samson and Paré, 2006). It should be noted that in our model, CREB (or intrinsic excitability) did not determine the initial connectivity of the cells. Instead, independently of whether particular principal cells were type A, B, or C, we set up probabilistic gradients of connectivity based on earlier physiological studies of the intrinsic LA network.

\section{Activity-dependent synaptic plasticity}

Model synapses could undergo activity-dependent synaptic plasticity, consistent with the experimental literature. All AMPA synapses in the model were endowed with long-term postsynaptic plasticity except for those delivering shock or background inputs. Also, all GABA synapses had long-term plasticity. This form of plasticity was implemented using a learning rule that uses the concentration of a postsynaptic calcium pool at each modifiable synapse (Shouval et al., 2002a,b). Calcium entered postsynaptic pools at excitatory synapses via NMDA receptors (and AMPA receptors for interneurons) and voltage-gated calcium channels (VGCCs). Similarly, calcium for pools at inhibitory synapses came from postsynaptic intracellular stores and VGCCs (Li et al., 2009). For both types of synapses, the synaptic weight decreased when the calcium concentration of the pool was below a lower threshold and increased when it exceeded an upper threshold. All model AMPA and GABA synapses also exhibited short-term presynaptic plasticity, with short-term depression at interneuron-principal cell and principal cell-interneuron connections. Additional details and equations related to the implementation of these plasticity mechanisms can be found in Kim et al. (2013).

\section{Neuromodulator effects}

Neuromodulators have long been implicated in fear and anxiety, and are known to regulate pavlovian fear learning and synaptic plasticity in LA (Bissière et al., 2003; Tully and Bolshakov, 2010). Conditioned aversive stimuli alter the activity of ventral tegmental area and locus ceruleus neurons, which in turn modulate fear and anxiety through their widespread forebrain projections, including to the amygdala. Therefore, the 
model incorporated the effects of dopamine and norepinephrine on LAd cells, based on prior experimental reports.

\section{Inputs}

Background synaptic inputs. LA projection neurons have low spontaneous firing rates in control conditions (Gaudreau and Paré, 1996). To reproduce this, Poisson-distributed, random excitatory background inputs were delivered to all model cells, resulting in average spontaneous firing rates of $0.7 \mathrm{~Hz}$ for principal cells and $7.2 \mathrm{~Hz}$ for interneurons.

Tone and shock inputs. Auditory fear conditioning is thought to depend on the convergence of inputs relaying information about the CS (tone) and US (footshock) in LA (Quirk et al., 1995; LeDoux, 2000; Pape and Paré, 2010). In the model, the CS and US inputs were represented by glutamatergic synapses acting via AMPA and NMDA receptors. The frequency of thalamic and cortical tone inputs during habituation was set to $20 \mathrm{~Hz}$. The tone inputs also included noise represented by random Poisson spikes with an average frequency of $2 \mathrm{~Hz}$. The following distribution of inputs was used for the simulations: uniform total tone density throughout LAd, with $70 \%$ of the cells in the dorsal subdivision (LAdd) receiving thalamic tone projections and $35 \%$ receiving cortical tone projections; and the opposite for cells in the ventral subdivision (LAdv), i.e., $35 \%$ of LAdv cells receiving thalamic and $70 \%$ receiving cortical tone projections. The shock inputs were distributed uniformly to $70 \%$ of LAd cells.

\section{Conditioning protocol used in simulations}

The schedule of tone and shock inputs in the simulations was based on in vivo studies (Quirk et al., 1995). We scaled down the timing of the auditory fear-conditioning protocol so that it would be suitable for computational studies (Fig. 1B). The protocol included three phases (habituation, conditioning, and recall), composed of 8,16 , and 4 trials, respectively. Each trial featured a $0.5 \mathrm{~s}$ tone CS followed by a $3.5 \mathrm{~s}$ gap. Only during conditioning, a shock was administered $100 \mathrm{~ms}$ before the end of the tone, so that they coterminated. In light of evidence that fear conditioning leads to plasticity in CS afferent pathways, the frequency of thalamic and cortical tone inputs was increased to $40 \mathrm{~Hz}$ after the first and sixth conditioning trials, respectively.

All model runs were performed using parallel NEURON (Carnevale and Hines, 1006) running on a Beowulf supercluster with a time step of $10 \mu$ s. The primary model used in this study will be available on the ModelDB public database (http://senselab.med.yale.edu/ModelDB/) as part of our previous publication (Kim et al., 2013).

\section{Results}

It was previously reported that during fear conditioning only a minority of principal LA neurons $(\approx 25 \%)$ develop potentiated CS responses (Quirk et al., 1995; Repa et al., 2001; Rumpel et al., 2005), even though most receive the necessary inputs (Han et al., 2007). These investigators also noted that a similarly low proportion of LA cells displays CREB and that CREB enhances the likelihood that individual LA neurons are recruited into the fear memory trace. Surprisingly however, when CREB was overexpressed or downregulated in LA, the proportion of LA neurons recruited into the memory trace remained constant. This led Han et al. (2007) to propose that selection of particular LA neurons to the fear memory trace involves a competitive process.

Because CREB decreases the sAHP (Viosca et al., 2009; Benito and Barco, 2010), we considered the possibility that a higher intrinsic excitability confers a competitive advantage to LA neurons. We could investigate this possibility with our model because it is endowed with three types of principal cells with high (type A, 50\%), intermediate (type B, 30\%), or low (type C, 20\%) spike frequency adaptation (Fig. $1 E$ ), due to the differential expression of a $\mathrm{Ca}^{2+}$-dependent $\mathrm{K}^{+}$current, as observed experimentally (Faber et al., 2001; Faber and Sah, 2003; Power et al., 2011). Other than their differing intrinsic excitability, types $A, B$, and $\mathrm{C}$ neurons are identical; they received the same types and
Table 1. Number of afferent connections per principal model cell

\begin{tabular}{lll}
\hline Cell types & Monosynaptic excitatory $^{a}$ & Monosynaptic inhibitory $^{b}$ \\
\hline $\mathrm{A}(n=400)$ & $21.4 \pm 0.5$ & $20.4 \pm 0.4$ \\
$\mathrm{~B}(n=240)$ & $21.6 \pm 0.7$ & $20.5 \pm 0.5$ \\
$\mathrm{C}(n=160)$ & $21.6 \pm 0.4$ & $20.3 \pm 0.5$ \\
\hline
\end{tabular}

Values are given as average \pm SEM. Afferents are from all other cells of types $A, B$, and $C$.

${ }^{a} \mathrm{df}=2, F=0.046, p=0.955$ (by ANOVA). There were no significant differences among A, B, and ( groups $(p>0.05)$.

${ }^{b} \mathrm{df}=2, F=0.03, p=0.97$ (ANOVA). There were no significant differences among $\mathrm{A}, \mathrm{B}$, and $\mathrm{Cgroups}(p>0.05)$

numbers of inputs (Table 1). Therefore, if the model is valid and CREB biases principal cells to become part of the fear memory trace by increasing their intrinsic excitability, one would expect an over-representation of the more excitable principal neurons among the plastic cells.

Consistent with this prediction, we found that a negligible proportion of type A neurons was plastic cells, compared with around half of type B and C cells (Fig. $1 F$ ). Furthermore, when we simulated the $\mathrm{CREB}^{+}$or $\mathrm{CREB}^{-}$experiments of Han et al. (2007) by converting a randomly selected subset $(25 \%$ or 100 cells) of type A neurons to type $\mathrm{C}$, or type $\mathrm{B}$ or $\mathrm{C}$ neurons to type A, without altering their connectivity, the number of plastic cells did not change proportionally to the number of converted cells (Fig. 1G).

To analyze the mechanisms underlying this effect, we compared the extrinsic and intrinsic connectivity of plastic versus nonplastic cells in the control case. Note that the connectivity of the model was not determined arbitrarily (Kim et al., 2013). Instead, we used probabilistic gradients of excitatory and inhibitory connectivity so that the model would reproduce prior experimental observations about the spatially heterogeneous intrinsic connectivity that exists in different parts of LA (Pape and Paré, 2010). Note that CREB status and connectivity were determined independently in our model. However, the intrinsic excitability of the cells, in concert with the connections formed by each cell, alters the likelihood that existing inputs will undergo activitydependent plasticity. All values reported below are averages \pm SEM, except for cell counts.

With respect to extrinsic connections, a higher proportion of plastic cells received tone inputs from the thalamus and/or cortex (100\%) than nonplastic type B or C cells $\left(61 \% ; \chi^{2}=6.8, p<\right.$ $0.05)$. Shock inputs were also more prevalent in plastic $(94 \%)$ than in nonplastic type B or C cells (47\%); excitatory connections from other plastic cells that receive shock inputs drove plasticity in the cells of the former group that did not receive shock inputs. Intrinsic connections also differed between the two cell types (Fig. 2): plastic cells formed more monosynaptic excitatory connections $(5.8 \pm 0.23)$ with other plastic cells, compared with nonplastic cells $(4.1 \pm 0.15 ; p<0.0001$; Fig. $2 A)$. In addition, there were more disynaptic connections involving interneurons from plastic to nonplastic cells $(131 \pm 4.1)$ compared with such connections between plastic cells ( $108 \pm 4$; $p<0.0001$; Fig. $2 B)$. Importantly, the same differences in intrinsic connectivity were observed between plastic and nonplastic cells of types A-C as well as in the $\mathrm{CREB}^{+}$and $\mathrm{CREB}^{-}$simulations.

As mentioned above, in the $\mathrm{CREB}^{+}$and $\mathrm{CREB}^{-}$simulations (Fig. 1G), the number of plastic cells did not change proportionally to the number of cells whose intrinsic excitability was altered. This occurred because some of the originally plastic cells became nonplastic (hereafter termed "loser cells") and others, originally nonplastic, became plastic (hereafter termed "winner cells"). We reasoned that contrasting the 

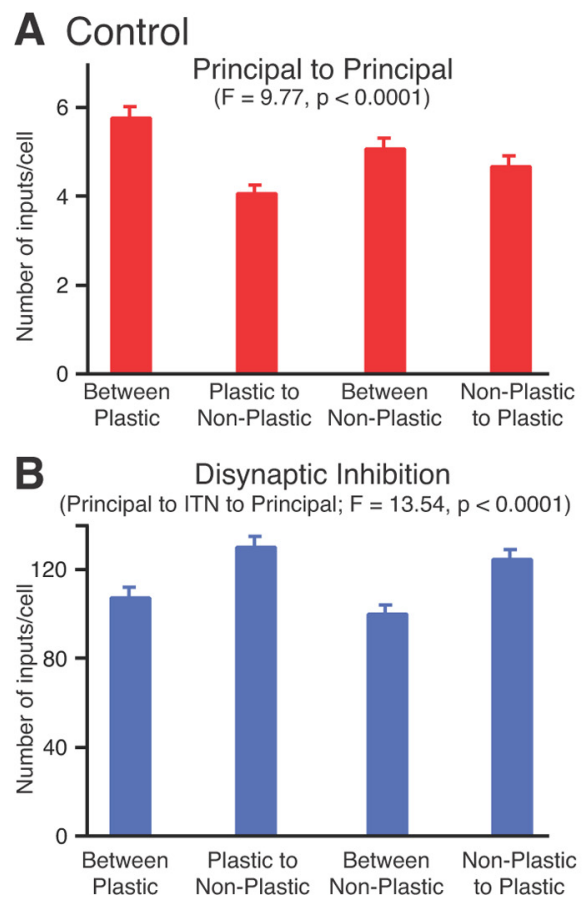
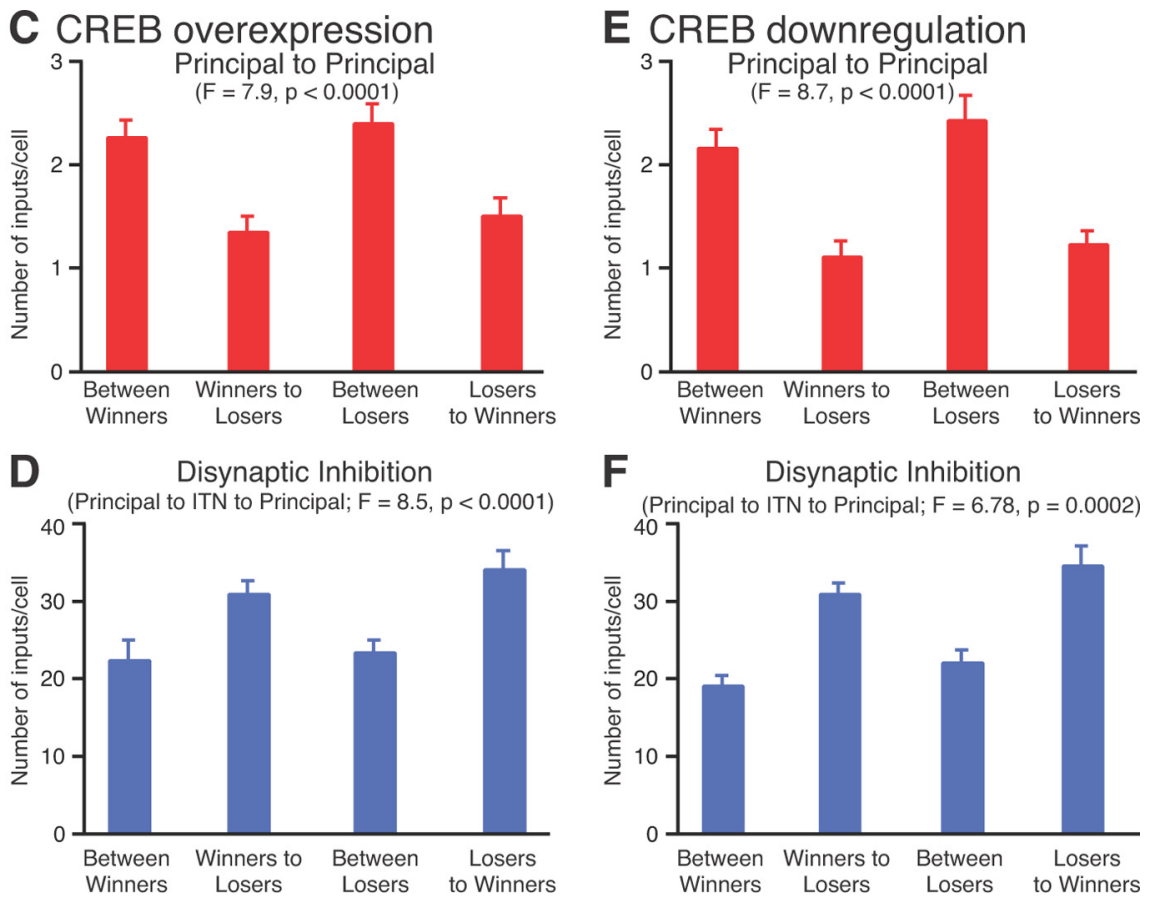

F Disynaptic Inhibition

(Principal to ITN to Principal; $F=6.78, p=0.0002$ )

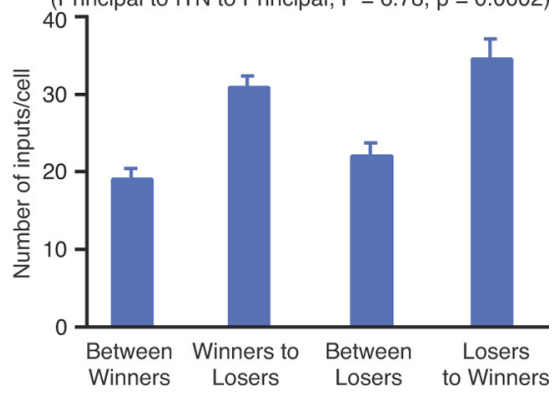

Figure 2. Differential intrinsic connectivity supports competition. $\boldsymbol{A}-\boldsymbol{F}$, Monosynaptic excitatory $(\boldsymbol{A}, \boldsymbol{C}, \boldsymbol{E})$ and disynaptic inhibitory $(\boldsymbol{B}, \boldsymbol{D}, \boldsymbol{F})$ connections among as well as between plastic and nonplastic cells ( $x$-axis) in the control case. $\boldsymbol{C}-\boldsymbol{F}$, Connections of type $B$ or $C$ winner and loser cells in the $C_{R E B}{ }^{+}(\boldsymbol{C}, \boldsymbol{D})$ and $C R E B-(\boldsymbol{E}, \boldsymbol{F})$ simulations. $\boldsymbol{A}$ and $\boldsymbol{B}$ consider connections between all plastic and nonplastic principal cells. In contrast, $\mathbf{C}-\boldsymbol{F}$ consider connections between the subsets of plastic or nonplastic cells only, and so the numbers are smaller. Data are averages \pm SEM.

properties of these two cell types would shed light on the factors involved in the competitive process.

This analysis revealed that in the $\mathrm{CREB}^{+}$and $\mathrm{CREB}^{-}$simulations, virtually all type B or C loser cells $(n=47$ and 9 , respectively) and winner cells ( $n=45$ and 28 , respectively) received tone and shock inputs. However, as for the control case (Fig. 2A), type $\mathrm{B}$ or $\mathrm{C}$ loser cells received significantly fewer monosynaptic excitatory connections from type $\mathrm{B}$ or $\mathrm{C}$ winner cells, compared with such connections between winner cells ( $p \leq 0.001$ in both cases; Fig. 2C,E). Moreover, the disynaptic connections from the winner cells involving interneurons to the loser cells were significantly more numerous than between winner cells ( $p \leq 0.015$ in both cases; Fig. $2 D, F)$. Surprisingly, however, loser cells lost the competition even though they received as many (and in fact slightly more) excitatory connections from other loser cells than between winner cells (Fig. 2C,E). Also, the incidence of disynaptic inhibitory connections between loser cells and winner cells was also comparable (Fig. 2D,F). This suggests that pre-existing differences in the connections of the two cell types are not the only factors that bias the cells to win or lose. Consistent with this, the proportion of type $C$ cells was significantly higher among winner cells compared with loser cells for the $\mathrm{CREB}^{+}$and $\mathrm{CREB}^{-}$cases $\left(\mathrm{CREB}^{+}: 96\right.$ vs $47 \%, \chi^{2}=58.9, p<0.0001$ CREB $^{-}: 64$ vs $33 \%$, $\left.\chi^{2}=19.2, p<0.0001\right)$. All other properties examined did not differ.

To test the robustness of the above findings, we performed additional simulations with different random values for (1) the distribution of the various types of principal cells in 3-D space, (2) afferent tone and shock connectivity, and (3) intraLAd connectivity. These simulations replicated the results reported above, indicating the robustness of the model for these parameters.

The outputs were very similar across models for the number of plastic cells $(189.3 \pm 6.5)$, the number of excitatory $(21.3 \pm 0.4)$ and inhibitory $(22.2 \pm 0.5)$ connections received by principal cells, the number of excitatory $(22.7 \pm 0.8)$ connections received by interneurons, and the tone responses of plastic cells. These numbers are comparable to the data in Figure $1 G$ and Table 1.

The $\mathrm{CREB}^{+}$and $\mathrm{CREB}^{-}$cases also gave similar results for the number of plastic cells across the cases. The difference across models was very small, as follows: $189.3 \pm 6.5$ for control; to $195.3 \pm 1.4$ for the $\mathrm{CREB}^{+}$case; and to $183.3 \pm 4.7$ for the $\mathrm{CREB}^{-}$case (similar to the data in Fig. $1 G$ ). Also, in all cases, plastic cells received more monosynaptic excitatory connections $(5.65 \pm 0.27)$ from other plastic cells compared with nonplastic cells $(3.85 \pm 0.33 ; p<0.001)$. In addition, there were more disynaptic connections from plastic to nonplastic cells (130.8 \pm 3.3) involving interneurons compared with such connections from nonplastic to plastic cells $(97.7 \pm 3.2)$. These again matched the data for the main model.

Furthermore, we repeated the runs with a second model (Kim et al., 2013) that was similar in all respects to the present one except for different initial weights of intra-LAd synapses. Considering the fact that the distributions of afferents, internal connectivity, and single-cell properties were based on experimental data, the only parameters for which we did not have very definitive data were initial synaptic weights and plasticity thresholds. Therefore, we also investigated whether alternative models might exist that provide output similar to that of the present one by varying these parameters. With a different set of initial weights and minor modifications to plasticity thresholds, we found another model (Kim et al., 2013, see parameter values for model 2) that replicated the above findings very well. A characteristic of this model was that inhibitory transmission within amygdala decreased (i.e., the interneuron-pyramidal cell connection was depressed) by $\sim 20 \%$ after conditioning (see also Rea et al., 2009), compared with the present model, where it increased slightly after conditioning. 


\section{Discussion}

The ability to associate fear responses with new stimuli or circumstances on the basis of experience is necessary for survival. There is evidence that the dorsal portion of the lateral amygdala is a critical site of plasticity for the storage of CS-US associations in pavlovian fear conditioning (LeDoux, 2000; Pape and Paré, 2010). However, it is not clear how the fear memory trace is formed. Here, we used computational modeling to test the hypothesis that assignment of particular LAd neurons to a memory trace involves a competitive process (Han et al., 2007), a notion based on the following observations. First, during fear conditioning only a minority of principal LA neurons $(\approx 25 \%)$ develop potentiated CS responses (Quirk et al., 1995; Repa et al., 2001; Rumpel et al., 2005), even though most receive the necessary inputs. Second, a similarly low proportion of LA cells displays activated CREB, and CREB enhances the likelihood that individual LA neurons are recruited into the fear memory trace (Han et al., 2007). Third, when CREB is overexpressed or downregulated in LA, the proportion of LA neurons recruited into the memory trace remains constant (Han et al., 2007).

Because CREB decreases the sAHP (Viosca et al., 2009; Benito and Barco, 2010), we considered the possibility that a higher intrinsic excitability confers a competitive advantage to LA neurons. Consistent with this view, we observed that only $0.7 \%$ model LA neurons with high spike frequency adaptation were plastic cells, compared with approximately half of the intrinsically more excitable neurons. However, if this factor (intrinsic excitability) acted independently, CREB overexpression would result in the recruitment of a higher number of LA cells to the memory trace. Yet, this was not seen experimentally (Han et al., 2007) or in the current model when CREB overexpression was simulated by converting less into more excitable cells. Similarly, CREB downregulation did not result in a lower number of plastic model cells in the memory trace, again replicating experimental observations. This suggested that additional factors are involved in the competitive process. Comparative analyses of the intrinsic connectivity of plastic versus nonplastic cells revealed that a major substrate of this competition is the distribution of excitatory connections between principal cells and the amount of disynaptic inhibition they generate in other projection cells. These two factors conspire to enhance the likelihood that some principal cells will fire more strongly to the CS and US at the expense of others. Effectively, this suggests that subsets of intrinsically more excitable projection cells band together by virtue of their excitatory interconnections to suppress plasticity in other projection cells via the recruitment of inhibitory interneurons. An important challenge for future experiments will be to test these predictions.

\section{References}

Benito E, Barco A (2010) CREB's control of intrinsic and synaptic plasticity: implications for CREB-dependent memory models. Trends Neurosci 33: 230-240. CrossRef Medline

Bissière S, Humeau Y, Lüthi A (2003) Dopamine gates LTP induction in lateral amygdala by suppressing feedforward inhibition. Nat Neurosci 6:587-592. CrossRef Medline

Carnevale NT, Hines ML (2006) The NEURON book. Cambridge, UK: Cambridge UP.

Faber ES, Sah P (2003) Ca2+-activated K+ (BK) channel inactivation contributes to spike broadening during repetitive firing in the rat lateral amygdala. J Physiol 552:483-497. CrossRef Medline
Faber ES, Callister RJ, Sah P (2001) Morphological and electrophysiological properties of principal neurons in the rat lateral amygdala in vitro. J Neurophysiol 85:714-723. Medline

Gaudreau H, Paré D (1996) Projection neurons of the lateral amygdaloid nucleus are virtually silent throughout the sleep-walking cycle. J Neurophysiol 75:1301-1305. Medline

Han JH, Kushner SA, Yiu AP, Cole CJ, Matynia A, Brown RA, Neve RL, Guzowski JF, Silva AJ, Josselyn SA (2007) Neuronal competition and selection during memory formation. Science 316:457-460. CrossRef Medline

Han JH, Kushner SA, Yiu AP, Hsiang HL, Buch T, Waisman A, Bontempi B, Neve RL, Frankland PW, Josselyn SA (2009) Selective erasure of a fear memory. Science 323:1492-1496. CrossRef Medline

Kim D, Paré D, Nair SS (2013) Mechanisms contributing to the induction and storage of Pavlovian fear memories in the lateral amygdala. Learn Mem 20:421-430. CrossRef Medline

LeDoux JE (2000) Emotional circuits in the brain. Annu Rev Neurosci 23: 155-184. CrossRef Medline

Letzkus JJ, Wolff SB, Meyer EM, Tovote P, Courtin J, Herry C, Lüthi A (2011) A disinhibitory microcircuit for associative fear learning in the auditory cortex. Nature 480:331-335. CrossRef Medline

Li G, Nair SS, Quirk GJ (2009) A biologically realistic network model of acquisition and extinction of conditioned fear associations in lateral amygdala neurons. J Neurophysiol 101:1629-1646. CrossRef Medline

Pape HC, Pare D (2010) Plastic synaptic networks of the amygdala for the acquisition, expression, and extinction of conditioned fear. Physiol Rev 90:419-463. CrossRef Medline

Power JM, Bocklisch C, Curby P, Sah P (2011) Location and function of the slow afterhyperpolarization channels in the basolateral amygdala. J Neurosci 31:526-537. CrossRef Medline

Quirk GJ, Repa C, LeDoux JE (1995) Fear conditioning enhances short latency auditory responses of lateral amygdala neurons: parallel recordings in the freely behaving rat. Neuron 15:1029-1039. CrossRef Medline

Rea K, Lang Y, Finn DP (2009) Alterations in extracellular levels of gammaaminobutyric acid in the rat basolateral amygdala and periaqueductal gray during conditioned fear, persistent pain and fear-conditioned analgesia. J Pain 10:1088-1098. CrossRef Medline

Repa JC, Muller J, Apergis J, Desrochers TM, Zhou Y, LeDoux JE (2001) Two different lateral amygdala cell populations contribute to the initiation and storage of memory. Nat Neurosci 4:724-731. CrossRef Medline

Rumpel S, LeDoux J, Zador A, Malinow R (2005) Postsynaptic receptor trafficking underlying a form of associative learning. Science 308:83-88. CrossRef Medline

Samson RD, Paré D (2006) A spatially structured network of inhibitory and excitatory connections directs impulse traffic within the lateral amygdala. Neuroscience 141:1599-1609. CrossRef Medline

Shouval HZ, Bear MF, Cooper LN (2002a) A unified model of NMDA receptor-dependent bidirectional synaptic plasticity. Proc Natl Acad Sci U S A 99:10831-10836. CrossRef Medline

Shouval HZ, Castellani GC, Blais BS, Yeung LC, Cooper LN (2002b) Converging evidence for a simplified biophysical model of synaptic plasticity. Biol Cybern 87:383-391. CrossRef Medline

Tully K, Bolshakov VY (2010) Emotional enhancement of memory: how norepinephrine enables synaptic plasticity. Mol Brain 3:15. CrossRef Medline

Tuunanen J, Pitkänen A (2000) Do seizures cause neuronal damage in rat amygdala kindling? Epilepsy Res 39:171-176. CrossRef Medline

Viosca J, Lopez de Armentia M, Jancic D, Barco A (2009) Enhanced CREBdependent gene expression increases the excitability of neurons in the basal amygdala and primes the consolidation of contextual and cued fear memory. Learn Mem 16:193-197. CrossRef Medline

Weinberger NM (2011) The medial geniculate, not the amygdala, as the root of auditory fear conditioning. Hear Res 274:61-74. CrossRef Medline

Zhou Y, Won J, Karlsson MG, Zhou M, Rogerson T, Balaji J, Neve R, Poirazi P, Silva AJ (2009) CREB regulates excitability and the allocation of memory to subsets of neurons in the amygdala. Nat Neurosci 12:14381443. CrossRef Medline 